\title{
IAC-04-I.2.06
}

\section{ROBUSTNESS OF THE KALMAN FILTER APPLICATION TO ESTIMATE STATES OF A SPACE FLEXIBLE SYSTEM}

\author{
Rolf Vargas, L.C. Gadelha DeSouza, Hélio K. Kuga \\ Space Mechanics and Control Division - DMC \\ National Institute for Space Research - INPE \\ Avenida dos Astronautas, 1758 - P.O. Box 515 \\ 12201-940 - São José dos Campos, S.P., Brazil \\ rhvv@hotmail.com, gadelha@dem.inpe.br, hkk@dem.inpe.br
}

\begin{abstract}
Nowadays, satellites with rigid and flexible components are increasingly being extended to advanced applications, where solar panels, communication antennas, telescopic structures and robotics arms must achieve better pointing accuracy requirements. On the other hand, the guaranty of the controller performance depends not only on its good design but also on the knowledge of all states to be fed-back in order to improve the overall control system efficiency. As a result, control system design methods that include parameters identification and/or states estimation need more investigation to know their capability and limitations. In this paper, a Kalman filter methodology is used to recover the unmeasured states (elastic displacement and its rates) considering that only the states associated with rigid motion are measured (angle and angular velocity). In order to investigate the robustness of the filter, the Kalman filter methology is tested with a satellite model compose of one, two and three flexible modes. One observes that the fidelity of the estimation process increase with the inclusion of more modes in the satellite model, which in turn not affect the performance of the Kalman filter procedure.
\end{abstract}

\section{Introduction}

The use of small satellites has been a fast, simple and low cost way of reaching the space in missions with the most several applications ${ }^{1,2}$, however, in order to conquer the space it is necessary to launch spacecraft that involves rigid/flexible structures. These missions are more complex because the satellites have a great number of components like, solar panels, antennas, cameras and mechanical manipulators. As a results, the influence of the flexibility of such structure play a important role in the dynamics behavior as well as in the performance of the Attitude Control System (ACS) ${ }^{3}$. Others important aspects in the study of the dynamics and control of flexible space structures are: the degree of interaction between the rigid and flexible motion, maintenance of the ACS performance in face the uncertainties of the mathematical model, damping residual vibrations in order to keep pointing precision and dynamic parameters identification. ${ }^{4}$ This paper presents an estimation procedure using the Kalman Filter methodology in order to estimate the elastic displacement and its rate in space. Section 2 presents a mathematical model of a simple spacecraft based on a flexible EulerBernoulli beam connected to a rigid hub. The equations of motion are derived using the Lagrange approach, where noise is introduced to corrupts the input and the angles and angular velocities, which are the outputs of the system. Section 3 presents the Kalman filter estimation algorithm. Section 4 presents the simulation where the Kalman filter is tested considering the satellite model with one, two and three flexible modes. Section 5 concludes the paper. 


\section{Spacecraft Mathematical Model}

The satellite mathematical model used is composed of a rigid platform with two flexible appendixes and masses in the extremities of the appendices. The appendices are identical and opposite, being considered as beam connected to the platform, and subjects to rotational and vibrational motion. In order to derive the equations of motion for this model, one applies the Lagrange methodology, starting from the expression of the kinetics and potential energy of the system. Fig. 1 illustrates the system composed by rigid hub and an elastic appendage.

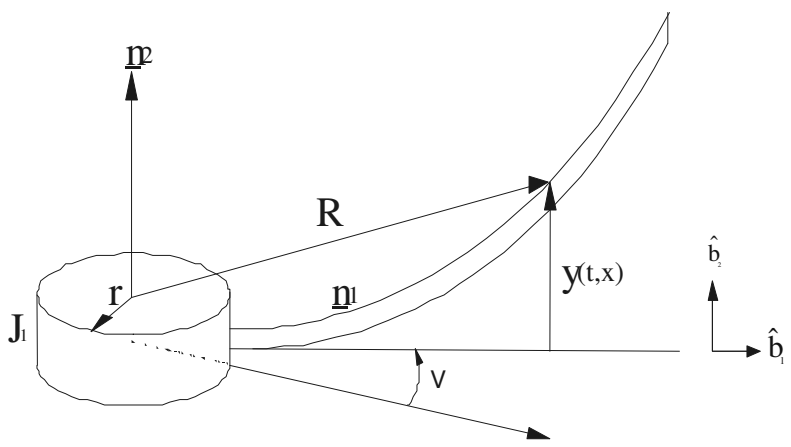

FIGURE 1. SATELLITE MODEL COMPOSED BY A RIGID HUB AND AN ELASTIC APPENDAGE.

One considers that the inertial reference system, coincides with the origin of the fixed reference system in the rigid body and it is represented by the axes $n_{1}, n_{2}, n_{3}$. The fixed reference system in the rigid body coincides with the center of mass of the rigid body, which is characterized by the axes $b_{1}, b_{2}, b_{3}$. The vector $r$ represents the radius of the rigid body. The vector $x$ represents a position of a measured mass element along the appendix in the no deformed form, in relation to the appendage reference system. $R$ gives the vector position of any point in the appendage relative to the inertial reference system. The vector of elastic displacement (elastic deformation) measured perpendicular to the axis $b_{1}$ is represented by y $(x, t)$. Therefore, the vector position of any point in the deformed appendage form, relative to the inertial reference system is given for:

$$
\underline{\mathrm{R}}_{1}=(\mathrm{r}+\mathrm{x}) \underline{\mathrm{b}}_{1}+\mathrm{y} \underline{\mathrm{b}}_{2}
$$

and its velocity vector is

$$
\underline{\mathrm{R}}=\frac{\mathrm{d}}{\mathrm{dt}}(\underline{\mathrm{R}})_{\mathrm{N}}=\frac{\mathrm{d}}{\mathrm{dt}}(\underline{\mathrm{R}})_{\mathrm{B}}+\underline{\omega} \times \underline{\mathrm{R}}
$$

Considering that $\dot{\theta}$ is the satellite angular velocity and substituting Eq. (1) into (2), one has

$$
\underline{\dot{\mathrm{R}}}=-\dot{\theta} \mathrm{y} \underline{\hat{\mathrm{b}}}_{1}+[\dot{\theta}(\mathrm{r}+\mathrm{x})+\dot{\mathrm{y}}] \underline{\hat{\mathrm{b}}}_{2}
$$

\section{Equation of Motion}

The total kinetics energy of the system is given by

$$
\mathrm{T}_{\mathrm{T}}=\frac{1}{2} \mathrm{~J}_{\mathrm{h}} \dot{\theta}^{2}+2 \int_{0}^{\mathrm{L}} \rho\left\{\dot{\mathrm{y}}^{2}+2 \dot{\mathrm{y}} \dot{\theta}(\mathrm{r}+\mathrm{x})+\dot{\theta}^{2}(\mathrm{r}+\mathrm{x})^{2}\right\} \mathrm{dx}
$$

where $J_{h}$ is the rotary inertial of the hub, $\rho$ is the mass density of the appendages, $\mathrm{L}$ is the length of the appendage and $y(x, t)$ represents the elastic displacement.

The total potential energy $\mathrm{V}$ is considered as entirely due to the elastic deformations of the system and it is given by

$V_{T}=\int_{0}^{L}(E I)\left(\frac{d^{2} y}{d x^{2}}\right)^{2} d x$

where $\mathrm{E}$ represents the module of elasticity (module of Young) and I the moment of inertia of the beam. The discretization of the system is done using assumed mode method. ${ }^{5}$ Therefore, the elastic displacement $\mathrm{y}(\mathrm{x}, \mathrm{t})$ is substituted by

$y(x, t)=\sum_{1}^{N} \phi_{j}(x) q_{j i}(t)$

where $\phi_{\mathrm{j}}(\mathrm{x})$ is the admitted functions and $\mathrm{q}_{\mathrm{ji}}(\mathrm{t})$ are the generalized coordinates. The equations of motion are found for the rotation $\theta(\mathrm{t})$ and elastic $q(\mathrm{t})$ motion, using the Lagrange formulation

$\frac{\mathrm{d}}{\mathrm{dt}}\left(\frac{\partial \mathrm{T}}{\partial \dot{\mathrm{x}}_{\mathrm{i}}}\right)-\frac{\partial \mathrm{T}}{\partial \mathrm{x}_{\mathrm{i}}}+\frac{\partial \mathrm{V}}{\partial \mathrm{x}_{\mathrm{i}}}=\mathrm{F}_{\mathrm{x}_{\mathrm{i}}}, \quad(\mathrm{i}=1,2)$

where $F_{i}$ is the generalized force, and $x_{i}$ is the ith element of the vector (x).

Substituting the kinetic and potential energy expression into Eq.(7) and after some manipulation the equations of motion in the matrix form is given by 


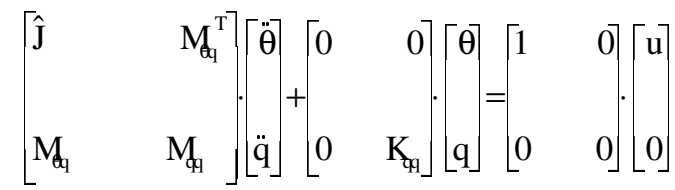

where $\hat{\mathbf{J}}$ is the total inertia moment of the system, $\mathbf{M}_{\theta \mathrm{q}}$ represents the sub-matrix associated with the rigid and flexible motion, $\mathrm{M}_{\mathrm{qq}}$ represents the sub-matrix associated with the flexible motion and $\mathrm{K}_{\mathrm{qq}}$ represents the submatrix associated with flexible body. Eq.(10) in compact form is given by

$\mathrm{M} \ddot{\mathrm{x}}+\mathrm{Kx}=\mathrm{Du}$

where $\mathrm{M}$ is the mass matrix, $\mathrm{K}$ is the stiffness matrix of the system and $\mathrm{D}$ is the control influence matrix. Eq.(11) in state space modal form is given by

$\tilde{\mathrm{M}} \ddot{\eta}(\mathrm{t})+\widetilde{\mathrm{C}} \dot{\eta}(\mathrm{t})+\widetilde{\mathrm{K}} \eta(\mathrm{t})=\tilde{\mathrm{D}} \mathrm{u}$

where $\tilde{\mathrm{M}}, \tilde{\mathrm{C}}, \quad \tilde{\mathrm{K}}$ and $\tilde{\mathrm{D}}$ represents mass, damping, stiffness and control influence matrices in modal form, respectively.

\section{Kalman Filter Estimation Algorithm}

The Kalman filter computational algorithm containing a sequence of time and measurement updating in order to estimates of the system state. ${ }^{6}$ The filter can incorporate dynamic noise in the dynamical model of the state. It is a real time estimator supplying the estimates for the instant that the measurement is available. The filter consists of two cycles:

- $\quad$ Time update

- Measurement update

The complete dynamical model is given by:

$\dot{\eta}_{1}=A \eta_{1}+G \omega$

where $\eta_{1}=[\eta, \dot{\eta}]^{\mathrm{T}}$ is the modal coordinates, $\omega$ is white gaussian noise, $G$ is matrix unitary.
The matrix $\mathrm{A}$ is the system matrix that relates the state linearly by

$A=\left[\begin{array}{cc}0 & I \\ -\tilde{K} & -\tilde{C}\end{array}\right]$

The measured model is given by:

$\mathrm{Y}=\mathrm{C} \eta_{1}+v$

the output is the angle $\theta$ and angular velocity $\dot{\theta}$, with standard deviation of $0.05^{\circ}$ and $0.005^{\circ} / \mathrm{s}$, respectively. The matrix is $\mathrm{C}=\mathrm{B}^{\mathrm{T}}$. The term $v$ represents a white noise vector with the following static

$v_{\theta}=\mathrm{N}\left(0,0.05^{\circ}\right), \quad v_{\dot{\theta}}=\mathrm{N}\left(0,0.005^{\circ} / \mathrm{s}\right)$

In the time update, the states are estimates using

$\dot{\overline{\mathrm{x}}}=\mathrm{A} \overline{\mathrm{x}}$

with initial conditions $\overline{\mathrm{x}}_{\mathrm{k}-1}=\hat{\mathrm{x}}_{\mathrm{k}-1}$, and the covariance is computed by

$\dot{\overline{\mathrm{P}}}=\mathrm{A} \overline{\mathrm{P}}+\overline{\mathrm{P}} \mathrm{A}^{\mathrm{T}}+\mathrm{GQG}^{\mathrm{T}}-\overline{\mathrm{P}} \mathrm{C}^{\mathrm{T}} \mathrm{R}^{-1} \mathrm{C} \overline{\mathrm{P}}$

with initial conditions $\overline{\mathrm{P}}_{\mathrm{k}-1}=\hat{\mathrm{P}}_{\mathrm{k}-1}$. Eq.(16) is known as Riccati equation.

In the measurement update the states and covariance matrix are calculated by

$$
\begin{aligned}
& \mathrm{K}_{\mathrm{k}}=\overline{\mathrm{P}}_{\mathrm{k}} \mathrm{C}^{\mathrm{T}}\left(\mathrm{C} \overline{\mathrm{P}}_{\mathrm{k}-1} \mathrm{C}^{\mathrm{T}}+\mathrm{R}\right)^{-1} \\
& \overline{\mathrm{P}}_{\mathrm{k}}=\left(\mathrm{I}-\mathrm{K}_{\mathrm{k}} \mathrm{C}\right) \overline{\mathrm{P}}_{\mathrm{k}-1} \\
& \hat{\mathrm{x}}_{\mathrm{k}}=\overline{\mathrm{x}}_{\mathrm{k}-1}+\mathrm{K}_{\mathrm{k}}\left(\mathrm{y}_{\mathrm{k}}-\mathrm{C} \hat{\mathrm{x}}_{\mathrm{k}-1}\right)
\end{aligned}
$$

where $\mathrm{K}$ represents the Kalman gain, and $\overline{\mathrm{P}}$ and $\hat{\mathrm{x}}$ are the covariance and the state updated.

The errors between the actual state and the estimated state is

$\Delta \varepsilon_{\mathrm{i}}=\mathrm{x}_{\mathrm{i}}-\hat{\mathrm{x}}_{\mathrm{i}}$ 


\section{Simulations}

The aim of the simulations is to implement and test the proposed Kalman filter methodology for estimation of the flexible mode (elastic displacement) considering that the rigid motion of satellite (angle and angular velocity) is available. The analysis is performed using Eq. (13) to Eq. (19), finding the error by Eq.(20). The simulations were carried out by computational implementation of the software in Mat lab language.

The structural parameters used in the simulations are: radius $r=0.3048 \mathrm{~m}$, density $\rho=47.89 \mathrm{Kg} / \mathrm{m}$, damping $\varsigma=0.2, \mathrm{~L}=1.2192 \mathrm{~m}, \mathrm{E}=7.735 \times 10^{9}$ $\mathrm{Kg} / \mathrm{m}^{2}, \quad \mathrm{I}=1.293 \times 10^{-10} \mathrm{Kg}^{*} \mathrm{~m}^{2} \quad \mathrm{~J}_{\mathrm{h}}=10.84$ $\mathrm{Kg}^{*} \mathrm{~m}^{2}$. The Kalman filter parameters and the initial conditions used given in table 1.

TABLE 1. INITIAL CONDITIONS AND TUNNED PARAMETERS OF THE KALMAN FILTER

\begin{tabular}{|l|l|l|l|l|l|}
\hline Symbol & $\begin{array}{l}\text { Initial } \\
\text { Values }\end{array}$ & Symbol & $\begin{array}{l}\text { Initial } \\
\text { Value }\end{array}$ & Symbol & $\begin{array}{l}\text { Initial } \\
\text { Value }\end{array}$ \\
\hline $\mathrm{G}$ & $\mathrm{I}_{4}$ & $\mathrm{P}_{\dot{\theta}}(\% / s)^{2}$ & $(10)^{2}$ & $\mathrm{Q}_{\dot{\theta}}(\% / s)^{2}$ & $10^{-6}$ \\
\hline $\mathrm{R}_{\theta}\left({ }^{0}\right)^{2}$ & $(0.05)^{2}$ & $\theta_{0}\left({ }^{0}\right)$ & $(0.1)$ & $\mathrm{P}_{\theta}\left({ }^{0}\right)^{2}$ & $(10)^{2}$ \\
\hline $\mathrm{R}_{\dot{\theta}}\left({ }^{0} / \mathrm{s}\right)^{2}$ & $(0.005)^{2}$ & $\dot{\theta}_{0}(\% / s)$ & $(0.01)$ & $\mathrm{Q}_{\dot{\mathrm{q}}}(\% / \mathrm{s})^{2}$ & $10^{-8}$ \\
\hline $\mathrm{Q}_{\theta}\left({ }^{0}\right)^{2}$ & $10^{-6}$ & $\mathrm{Q}_{\mathrm{q}}\left({ }^{0}\right)^{2}$ & $10^{-8}$ & $\mathrm{P}_{\mathrm{q}, \dot{\mathrm{q}}}\left({ }^{0}, / \mathrm{s}\right)^{2}$ & $(10)^{2}$ \\
\hline
\end{tabular}

The investigation philosophy is check first the behavior of the measurement residuals on $\theta$ and $\dot{\theta}$. After that, the robustness of the filter is verified increasing the order of the system. This is, the simulation has been done comparing the elastic displacement with a satellite model with one, two and three elastic modes.

Figure 2 shows the behavior of the measurement residuals on $\theta$ and $\dot{\theta}$ for satellite with one mode. In this case the residuals are in good shape with one standard deviation around $0.1^{\circ}$ and $0.01 \%$, respectively.

Figure 3 shows the difference between the ideal state and the estimate state the "error" for the satellite model with one, two and three modes. It can be seen that angular velocity estimated, remains in all modes, under the limits of standard deviation. But for the angle it is necessary 50 seconds for the filter to adapt and have a good performance.

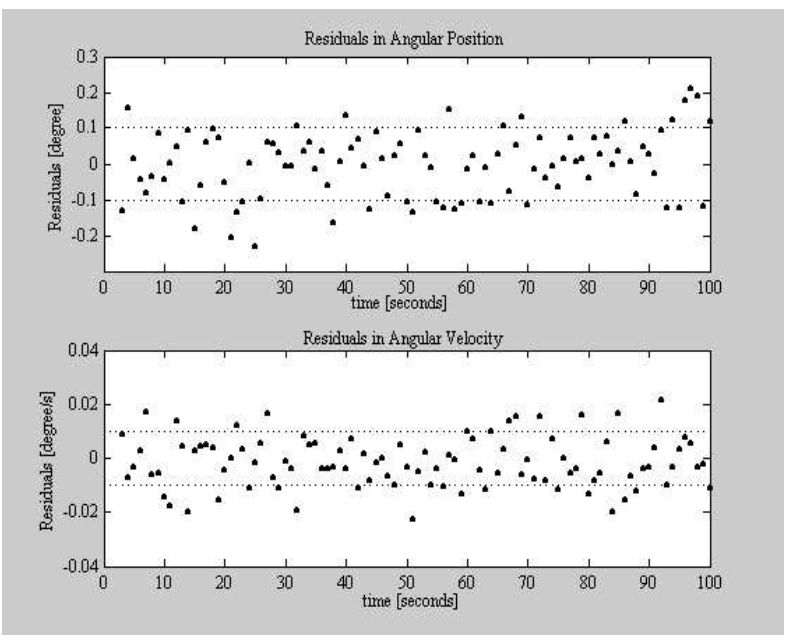

Figure 2 - the behavior of the measurement residuals on $\theta$ and $\dot{\theta}$.

Figure 4 shows a significant difference between the model with one and two modes in the flexible coordinate $\mathrm{q}_{1}$ and $\mathrm{q}_{2}$. However, that difference is negligible for the model with two and three modes, which means that the satellite can be modeled at most with two modes without lost of accuracy. This is correct because, when more modes are included, the dynamics of the system tend to stationary values.

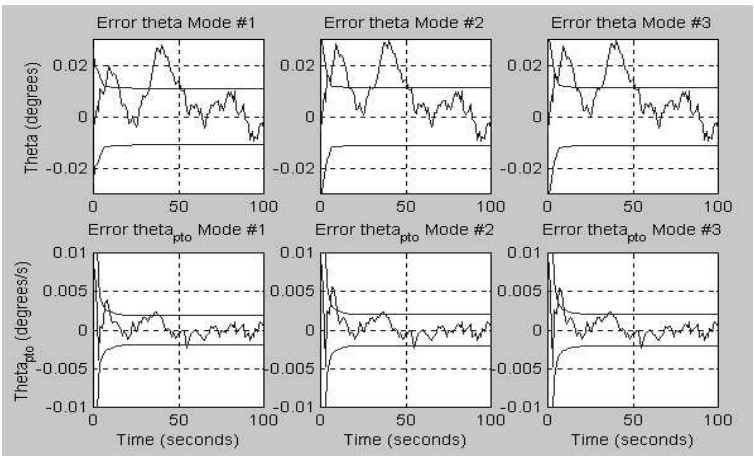

Figure 3 the error for the satellite model with one, two and three modes. 


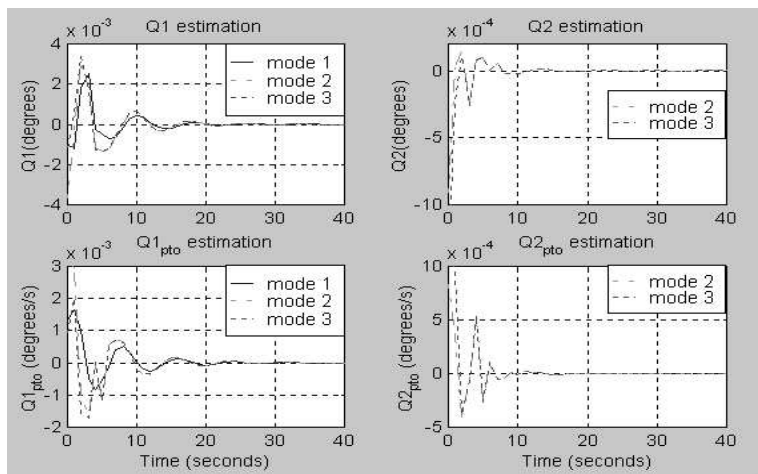

Figure 4 Estimation elastic displacement $\mathrm{q}_{1}, \mathrm{q}_{2}$.

\section{Conclusions}

In this work a satellite composed of a central rigid body and two flexible appendages was mathematically modeled to be used in an estimation methology based on Kalman filter. A Lagrangian formulation was used to derive the equations of motion of the satellite. The discretization of the elastic displacement was performed by the assumed mode method. The estimation of the elastic displacement was done for a satellite model with one, two and three modes. It was observed that the fidelity of the estimation process increase with the inclusion of more modes in the satellite model, without affecting the performance of the Kalman filter procedure. Having in mind the complexity of putting a sensor on the elastic parts of the satellite, the application of the Kalman filter methology has been showed a good approach to estimate indirectly the flexible parameters of a rigid-flexible satellite. That approach becomes more promising when it is necessary to feedback the elastic measurements into the control system in order to assure better pointing conditions and/or better system performance. Therefore, being an important tool in the estimation of estates in orbit.

\section{References}

[1] Souza, L.C.G.; Silva, S. A., "Vibration Control of a Rigid-Flexible Satellite During Attitude Maneuver". Publicação da ASME do $17^{\text {th }}$ Biennial Conference on Mechanical Vibration and Noise, 12-16, September, Las Vegas - Nevada, USA, 1999.
[2] Silva, A. R.; Schäfer, B.; Souza, L. C. G.; Fonseca, R. A., " Integrated Linear and Nonlinear Parameters Identification for Space Robot Dynamics".IAF-51st International Astronautical Congress. Out. 2000 - Rio de Janeiro, Brazil

[3] Silva, A.R.; Souza, L.C.G. "Control System Flexible Satellite Interaction During Orbit Transfer Maneuver". Published by American Astronautical Society (AAS) in Advances in the Astronautical Sciences, Vol. 100 Part I, pp. 541550, paper AAS 98-343, Ed. Thomas H. Stengle, USA, 1998. ISBN 0-87703-453-2

[4] Silva, A R., Schäfer, B., Souza, L.C.G., "Identification and Sensor Failure Detection Algorithms Applied to Space Robotic Joint". XI Colóquio Brasileiro de Dinâmica Orbital, Viçosa-MG, Brazil, 04 a 08 de novembro de 2002.

[5] Trigolo, A e Souza, L.C.G.; "Attitude Control System Performance of Satellite". Presented CBDO - Congresso Brasileiro de Dinâmica Orbital, 20-24 de novembro, - Nazaré Paulista - SP, 2000 - Brasil.

[6] Gelb, A.; Kasper Jr., J.F.; Nash Jr., R.A.; Price, C.F; Sutherland Jr., A.A. Applied Optimal Estimation. Inglaterra: The M.I.T Press, 1974. $374 p$. 